\title{
The Effect of Income Inequality on Property Crime: Evidence from Iran
}

\author{
*Najmeh Izadi, Khosrow Piraee \\ Islamic Azad University (Iran-Shiraz branch), Iran \\ *najmehi.963@gmail.com
}

\begin{abstract}
The main purpose of this study is to examine the relationship between income inequality and property crime rate, including auto theft, burglary and larceny, in Iran from 1984 to 2009. Income inequality measures include Gini coefficient and Atkinson index, with 1 and 2 degrees of inequality aversion $(e=1,2)$. Unrestricted error correction model (UECM)is employed to do bounds test and to examine the presence of cointegration. The results indicate that there is not any long-run relationship between income inequality and property crime rate.
\end{abstract}

Key Words: Income inequality, property crime, unrestricted error correction model (UECM)

\section{Introduction}

Over the recent decade, income inequality has risen in Iran. According to theories and empirical evidences, this inequality directly impresses criminal behaviors and particularly property crimes on which the current study is seeking for the effects of. Economic literature on crime is referred to the seminal works of Becker (1968) who considers the income inequality factor as a proxy to show the differences in legal and illegal gains. Hence he expected to find a positive correlation between income inequality and commissioning of crimes under the impression of three factors:

- Interrelationship between moral costs and psychological punishments;

- Economic motivation i.e. a comparison made between legal incomes and illegal gains which probably conducts to higher expected utility of illegal incomes;

- Arrest probability and severity of the punishments. It goes without saying that the greater the income inequality, the higher the will toward crime commission.

While Becker (1968) emphasizes on the cost and benefit of crime, Ehrlich (1973) extends Becker's crime model by including the role of opportunity cost between illegal and legal work. Ehrlich (1973) found a significant relationship between the crime rate and the share of the population below half the median income across the US states.

\section{Literature Review}

As explained in the early part of this paper, it cannot be denied that the seminal paper by Becker (1968) and Ehrlich (1973) have been considered as the most important work in crime studies. The empirical evidences on relationship between crime and inequality yield mixed results .Many of these studies found a strong positive relation between income inequality and crime, but a weak or nonexistence of the above relationship in other studies. Chiu and Madden(1998) presented a powerful link between worsening income inequality and increases in the number of burglarie. Kelly (2000)employed cross-sectional analyze for United States counties in 1991 and found a positive and significant effect of inequality on robbery, assault overall violent crime, but not on property crime. Fajnzylber et al. (2002b) strongly reported that increases in income inequality raise violent crime rate, in their study on several developed and developing countries for the period 1970-1994. Nilsson (2004)also found a strong link between property crime and income inequality in Sweden foe the period 1973-2000. Scorzafav and Soares (2009) used panel data in Brazil for the period 20022004 and concluded that income inequality has a positive effect on pecuniary crime rates. Keshavarz and Markazi (2010) employed panel data for provinces of Iran during 1997-2005 and found that Gini coefficient affects property crime positively. Allen (1996) derived that although income inequality affects robbery, it is not statistically significant. Bourguignon et al. (2003) found only insignificant results about the link between 
income inequality and overall crime rate. Mehanna (2004)concluded that income inequality has no important impact on crime in United States. Neumayer (2005) also failed to show a strong relationship between income inequality and robbery/theft during 1980-1997 in various countries. Brush (2007) conduct and compare cross-sectional and time series analyses of United States counties, interestingly, the results are in contradiction, income inequality is positively associated with crime rates in the cross section analysis, but it is negatively associated with crime rates in the time-series analysis. Choe (2008) found a positive impact of the Gini coefficient on burglary and robbery, but fails to find an impact on property crimes. Baharom and Habibullah (2009)didn't observe any crucial effect of income inequality on crimes in Malaysia for the period 1973-2003. Following Baharom and Habibullah (2009), in this paper, we employ bounds test to examine cointegration between income inequality and crime. It is important to notice that the current study merely focuses on property crime and neglects other crimes -an approach different from Baharom and Habibullah`s. We reach to the same result as Baharom and Habibullah did. There is no confirmed relationship between variables of each investigation. The remainder of the paper is organized as follows. After the introduction, methodology is discussed in section 2 . The results of the study are elaborated in section 3 . The conclusion and proposed suggestions are presented in the last part.

\section{Methodology}

Data: In this research, annual data for property crime rate and income inequality indices in Iran during 19842009 have been used. Income inequality measures include Gini coefficient and Atkinson index, with 1 and 2 degrees of inequality aversion $(e=1,2)$, Gini coefficient statistics have been taken from the central bank of Iran. Atkinson indices have been accounted by researchers 1. Property crime data have been available on the statistical year books (annual statistics) by statistical center of Iran.

Methodology and Model: In order to study a relationship between various measures of income inequality and property crime rate, the following double-log linear equation is estimated,

$$
\ln P_{t}=\alpha+\beta \ln I N Q_{t}+\varepsilon_{t}(1)
$$

Where $\ln P_{t}$ is the natural $\log$ of the property crime rate index/100,000population;lnINQ $Q_{t}$ is the natural $\log$ of measures of income inequality including Gini coefficient and Atkinson indices; $\alpha$ and $\beta$ are unknown parameters; $\varepsilon_{t}$ is the residual.The bounds test is done to examine the presence of cointegration .This test is an approach to testing for the existence of a relationship between variables in levels which is applicable irrespective of whether the underlying regressors are purely I(0), purely I(1) or mutually cointegrated.The bounds test is based on an estimation of the Unrestricted Error Correction Model (UECM)as follows:

$$
\ln P_{t}=\beta_{0}+\beta_{1} t+\pi_{1} \ln P_{t-1}+\pi_{2} \ln I N Q_{t-1}+\sum_{i=1}^{p} \lambda_{i} \Delta \ln P_{t-i}+\sum_{j=0}^{q} \delta_{j} \Delta \ln I N Q_{t-j}+\mu_{t}(2)
$$

$P$ and $q$ are optimal lags order length and are determined by information criteria such as AIC and SBC .To test the presence of long run relationship, we set $\mathrm{HO}: \pi 1=\pi 2=0$ versus $\mathrm{H} 1: \pi 1 \neq \pi 2 \neq 0$.According to Tang and Lean (2009), critical values which have been offered by Pesaran et al. (2001) are not appropriate for small sample sizes .Following them, we use critical values that Narayan (2005)provided .If the computed Fstatistics exceeds the respective upper critical bounds value, we conclude that the variables are cointegrated. If the F-statistics falls below the respective lower critical bounds, we fail to reject the null hypothesis of no cointegration relationship. If the F-statistics falls between its upper and lower critical bounds values, inference is inconclusive.

\section{Results and Discussion}

The ADF unit root test has been performed to investigate the degree of integration and has been found that all variables except Gini coefficient were non-stationary.The mentioned test confirmed stationary of Gini

\footnotetext{
${ }^{1}$ The data those are used to accounting Atkinson indices are available on the statistical year books. The information is not reported here but is available upon request.
} 
coefficient variable in its level .First differences of other variables were stationary. Research findings indicate that between Gini coefficient, Atkinson indices $(\mathrm{e}=1,2)$ and property crime rate accordingly $\mathrm{U}(3,2), \mathrm{U}(4,5), \mathrm{U}(4,5)$, are the best models which defined relations between mentioned inequality indices and property crime .The UECMs pass a numbers of diagnostic tests ${ }^{2}$.The plots of CUSUM and CUSUM of Squares tests are always inside the $5 \%$ confident lines which indicate the consistency of estimating parameters during period .The results of bound test for abovementioned inequality indices are as follows :2.12,3.23, 4.94; considering to the presented critical values by Narayan, it is clarified that there is not cointegration in all levels $(1 \%, 5 \%$, and $10 \%)$. In this study, such as Bourguignon (2003), Neumayer (2005), Mehanna (2004), Brush (2007), Choe (2008) and Baharom and Habibullah (2009) studies, which were mentioned in literature review section, the long run relationship between income inequality indices and property crime rate is not confirmed.

Note: In all tables $* *, * * *, *$ denote significance at $1 \%, 5 \%$ and $10 \%$ level.

Table 1: The estimated UECM for property crime(income inequality index is Gini coefficient).Unrestricted intercept and no trend ( $k=1$ and $T=30)$ from Narayan (2005).

\begin{tabular}{|c|c|c|}
\hline $\begin{array}{l}\text { Dependent variable } \Delta \ln S T_{t} \\
\text { Independent variables }\end{array}$ & Coefficient & t-statistics \\
\hline intercept & -18.5417 & $-1.8877 * * *$ \\
\hline $\operatorname{lnST} \mathrm{t}-1_{1}$ & -0.12777 & -1.1024 \\
\hline $\ln G_{t-1}$ & -21.1411 & $-2.016^{* * *}$ \\
\hline$\Delta \operatorname{lnST_{\mathrm {t}-1}}$ & -0.6067 & $-2.1108 * * *$ \\
\hline$\Delta \operatorname{lnST}_{\mathrm{t}-2}$ & 0.44643 & 1.4091 \\
\hline$\Delta \operatorname{lnST}_{\mathrm{t}-3}$ & -0.58132 & $-1.9324 * * *$ \\
\hline$\Delta \ln G_{t}$ & -1.7281 & -0.36968 \\
\hline$\Delta \ln G_{\mathrm{t}-1}$ & 22.3625 & $3.2363 *$ \\
\hline$\Delta \ln G_{\mathrm{t}-2}$ & 8.7325 & 1.5512 \\
\hline \multicolumn{3}{|l|}{ Bounds test F-statistics } \\
\hline Critical bounds & Lower & Upper \\
\hline $1 \%$ & 8.17 & 9.285 \\
\hline $5 \%$ & 5.395 & 6.35 \\
\hline $10 \%$ & 4.29 & 5.08 \\
\hline Conclusion :Non cointegrated & & \\
\hline
\end{tabular}

Adjusted R-squared :0.448; F-Statistic :2.1235[0.159];Ramsey RESET (1):0.81855[0.366]; Breusch-Godfrey LM test (1): 0.38831[0.533]; ARCH test (1):1.2454[0.264].

Figure 1: Respectively plots of CUSUM and CUSUM of squares statistics for the estimated UECM Property crime (income inequality index is Gini coefficient).

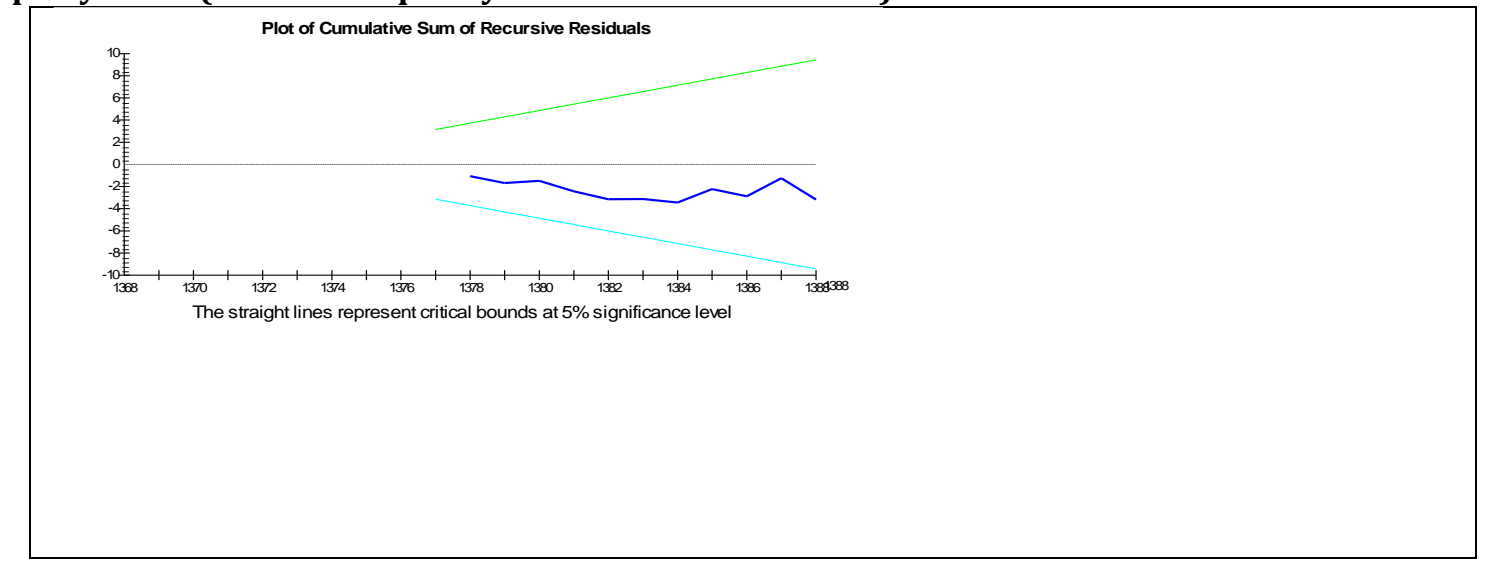

\footnotetext{
${ }^{2}$ The diagnostic tests confirm absent of heteroskedasticity (ARCH test), the Breusch-Godfrey LM test shows that the model is free from serial correlation problem .In addition, the model incorrectly specified (Ramsey RESET test).
} 


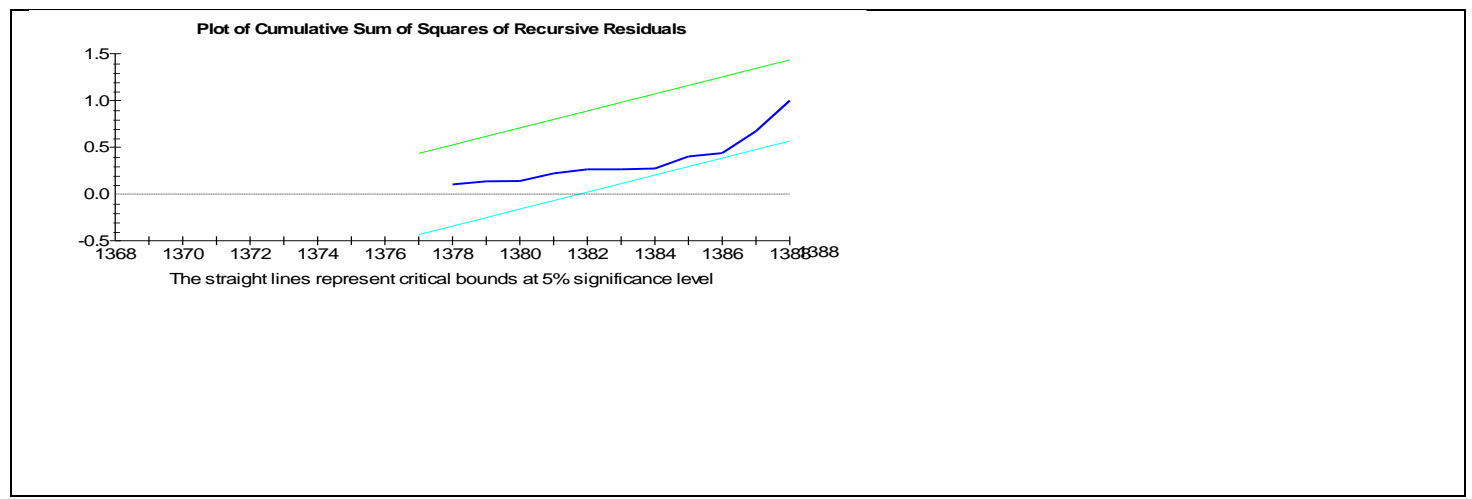

Table 2: The estimated UECM for property crime(income inequality index is Atkinson: $\mathrm{e}=1)$ Unrestricted intercept and unrestricted trend $(\mathrm{k}=1$ and $\mathrm{T}=30)$ from Narayan (2005).

\section{Dependent variable $\Delta \ln S T_{t}$ \\ Independent variables}

intercept

trend

$\operatorname{lnST} \mathrm{T}_{\mathrm{t}-1}$

$\ln \mathrm{E}(1)_{\mathrm{t}-1}$

$\Delta \operatorname{lnST}_{\mathrm{t}-1}$

Coefficient

$-1.9403$

$-0.1677$

0.48465

$-0.43885$

$-1.0343$

0.16467

$-1.7382$

$\Delta \operatorname{lnST} \mathrm{T}_{\mathrm{t}-3}$

$\Delta \operatorname{lnST}_{\mathrm{t}-4}$

$\Delta \operatorname{lnE}(1)_{\mathrm{t}}$

$\Delta \ln E(1)_{\mathrm{t}-1}$

$\Delta \operatorname{lnE}(1)_{\mathrm{t}-2}$

$\Delta \operatorname{lnE}(1)_{\mathrm{t}-3}$

$\Delta \operatorname{lnE}(1)_{\mathrm{t}-4}$

$\Delta \operatorname{lnE}(1)_{\mathrm{t}-5}$

Bounds test F-statistics

Critical bounds

$1 \%$

$5 \%$

$10 \%$

Conclusion :Non cointegrated

$-2.0253$

0.22469

0.601

0.37935

0.44778

0.60951

0.33438

t-statistics

$-1.2995$

$-2.1626^{* * *}$

1.2649

$-2.4072 * * *$

$-2.0365^{* * *}$

0.3133

$-2.8412 * *$

$-2.014^{* * *}$

1.9282

$2.9386^{* *}$

$1.9951^{* * *}$

$2.2468 * * *$

$2.8744^{* *}$

$2.0436 * * *$

Adjusted R-squared:0 .473; F-Statistic :3.2332[0.111]; Ramsey RESET (1):0.71204[0.399];Breusch-Godfrey LM test (1):4.3213[0.038]; ARCH test (1):1.4453[0.229].

Figure 2: Respectively plots of CUSUM and CUSUM of squares statistics for the estimated UECM Property crime ( income inequality index is Atkinson : $e=1$ ).

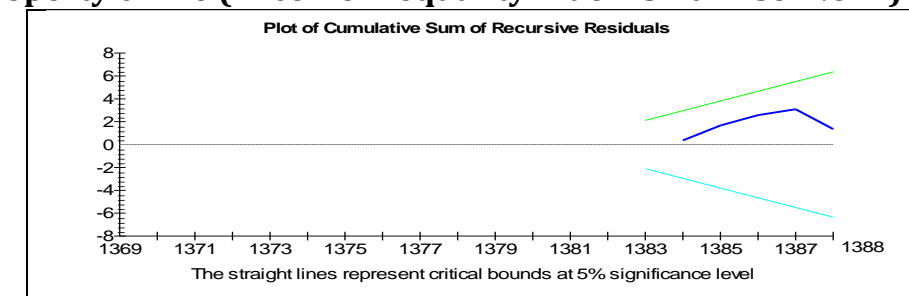




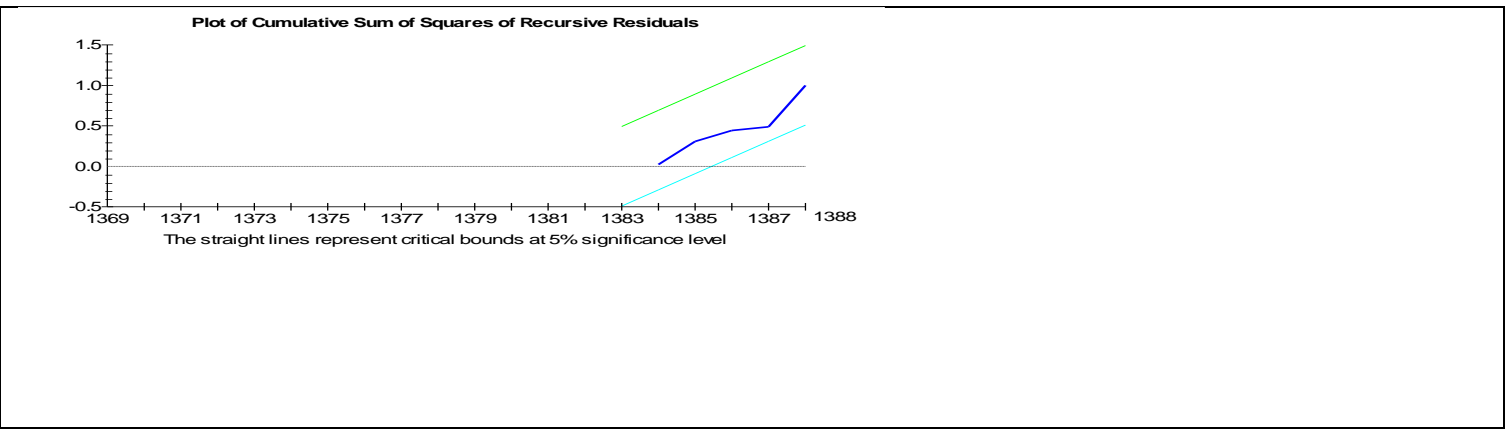

Table 3: The estimated UECM for property crime ( income inequality index is Atkinson : $\mathrm{e}=2$ ). Unrestricted intercept and unrestricted trend $(k=1$ and $T=30)$ from Narayan (2005).

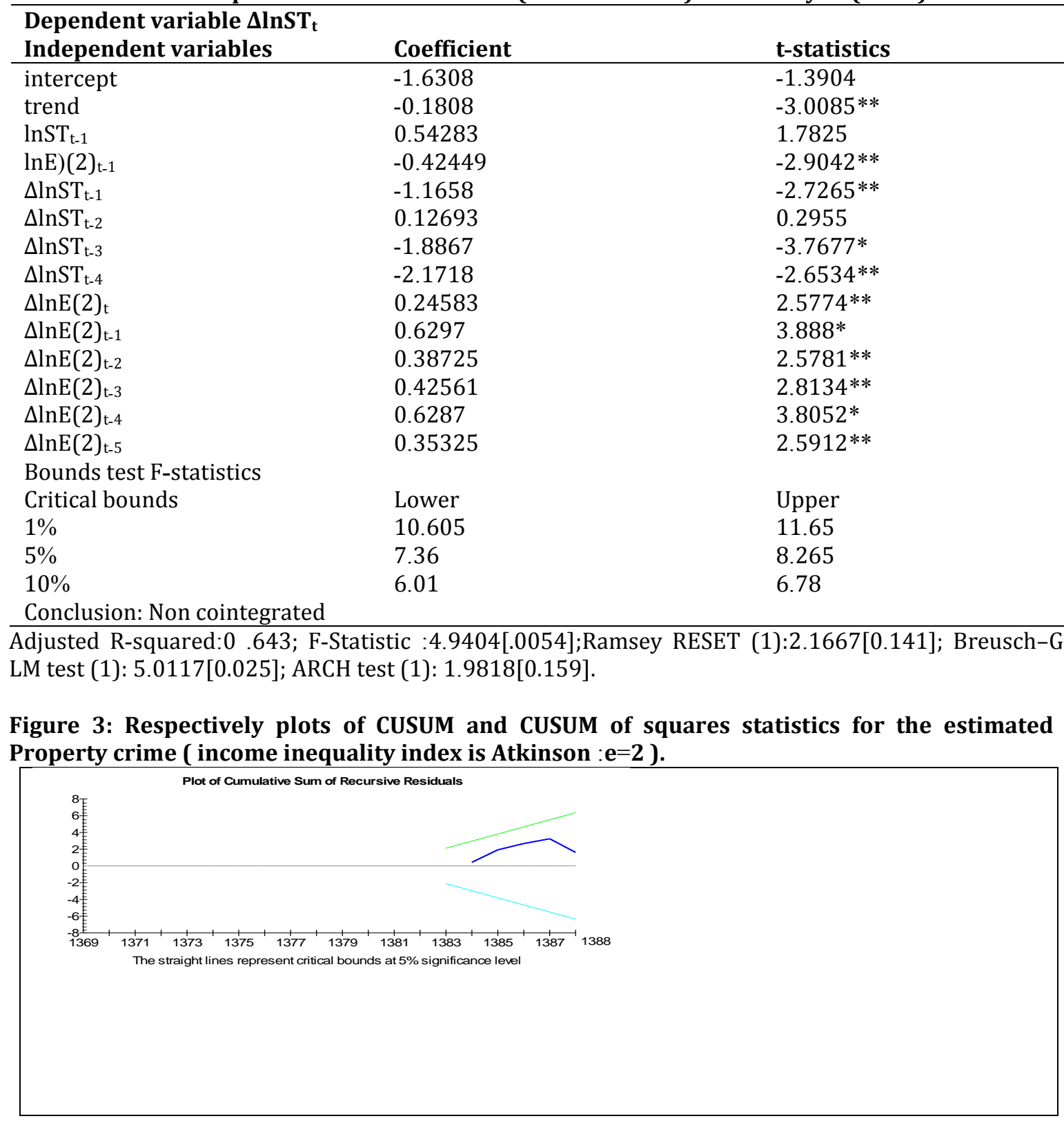




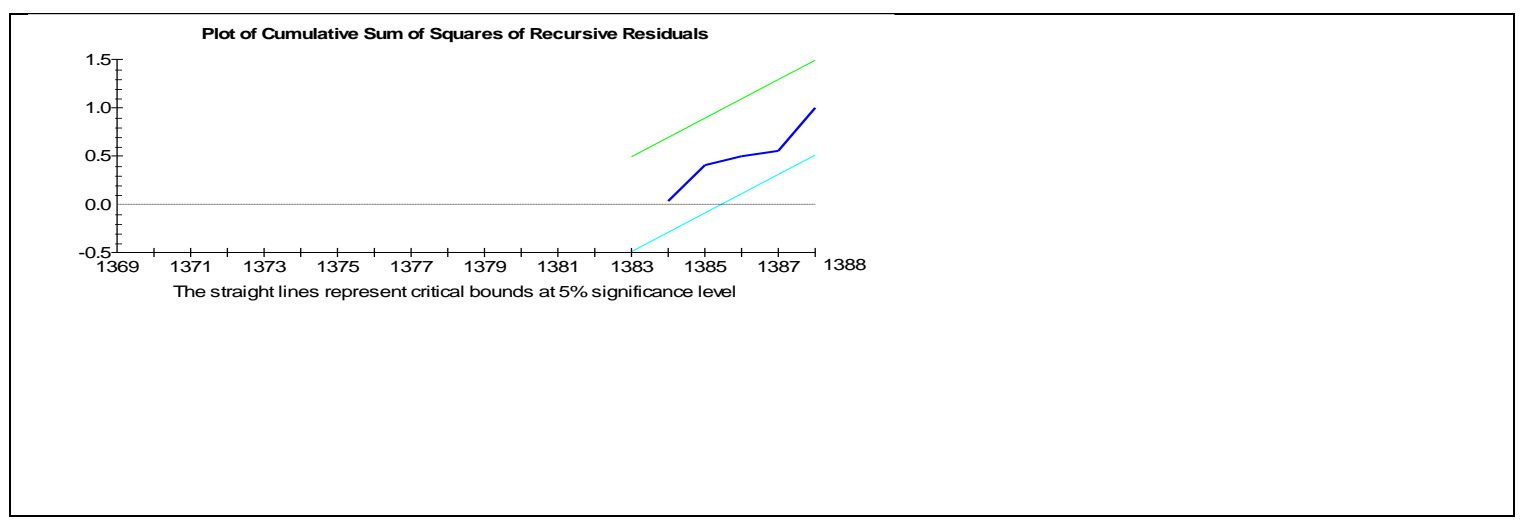

\section{Conclusion}

In this article, the effect of income inequality measures on property crime - in Iran- has been examined."It is not surprising that we couldn't find any relationship between variables because there are a number of studies, like Bourguignon(2003), Neumayer (2005), Mehanna (2004), Brush (2007), Choe (2008) and Baharom and Habibullah (2009),who could not find meaningful relationship between income inequality and crime. While income inequality is an important economic aspect of interest, the results shows that it is not cointegrated with property crime in Iran .It is recommended that in further studies, by considering predictable econometric problems, the influence of other socio-economic factors associated with income inequality on property crime be investigated.

Acknowledgement: We have greatly benefited from helpful suggestions made, in particular, by Dr. Moosavi Mohseni, Mr. Izadi, Ms. Barzegar M., Mrs. Abedi, Dr. Baharom and Dr. Habibullah. None of the above, however, is responsible for any remaining errors, omissions, which may only be attributable to us.

\section{References}

Allen, R. (1996). Socioeconomic conditions and property crime :a comprehensive review and test of the professional literature. American Journal of Economics and Sociology,55(3), 293-308.

Atkinson, A.B. (1970). On the measurement of inequality. Journal of Economic Theory, 2, 244-263.

Baharom, A. H. \& Habibullah, M. S. (2009). Crime and income inequality: The case of Malaysia. Journal of Politics and Law, 2(1), 55 - 77.

Becker, G. S. (1968).Crime and punishment: An economic approach. Journal of Political Economy, 76, 11691217.

Bourguignon, F., Nunez, J. \& Sanchez, F. (2003). What part of the income distribution does matter for explaining crime? The case of Colombia. Working Paper, Paris department et laboratoire D Economie Theorique et Appliquee (DELTA).

Brush, J. (2007). Does income inequality lead to more crime? A comparison of cross-sectional and time series analyses of United States countries. Economics Letters, 96, 264-268.

Chiu, W. H. \& Madden, P. (1998). Burglary and income inequality. Journal of Public Economics, 69, 123-141.

Choe, J. (2008). Income inequality and crime in the United States. Economics Letters, 101, 31-33.

Ehrlich, I. (1973). Participation in illegitimate activities: A theoretical and empirical investigation. Journal of Political Economy, 38(3), 521-565.

Fajnzylber, P., Lederman, D. \& Loayza, N. (2002a). What causes violent crime? European Economic Review, 46, 1323-1357.

Fajnzylber, P., Lederman, D. \& Loayza, N. (2002b). Inequality and violent crime. Journal of Law \& Economics, $45(1), 1-41$.

Fleisher, B. (1966). The effect of income on delinquency. American Economic Review, 56, 118-137.

Imrohoroglu, A., Merlo, A. \& Rupert, P. (2006). Understanding the determinants of crime. Journal of Economics and Finance, 30(2), 270-283.

Kelly, M. (2000). Inequality and crime. The Review of Economics and Statistics, 82(4), 530-539. 
Keshavarz-Haddad, G. H. \& Markazi-Moghadam, H. (2010). The socioeconomic and demographic determinants of crime in Iran (a regional panel study). Eur JLaw Econ. DOI 10. 1007/s10657-0109152-4.

Madden, P. \&Chiu, W.H. (1998).Burglary and income inequality. Journal of Public Economics,69, 123-141.

Narayan, P.K. (2005).The saving and investment nexus for China: Evidence from cointegration tests. Applied Economics, 37, 1979-1990.

Neumayer, E. (2005).Inequality and violent crime: Evidence from data on robbery and violent theft. Journal of Peace Research, 42(1), 101-112.

Nilsson, A. (2004). Income inequality and crime: The case of Sweden, Institute for Labor Market Policy Evaluation Working Paper.

Pesaran, M. H., Shin, Y. \& Smith, R. J. (2001).Bounds testing approaches to the analysis of level relationship. Journal of Applied Econometrics, 16, 289-326.

Scorzafave, L.G. \& Soares, M.K. (2009).Income inequality and pecuniary crimes. Economics Letters, 104, 40 42.

Tang, C. F. \& Lean, H. H. (2009). New evidence from the misery index in the crime function. Economics Letters, $104,112-115$. 